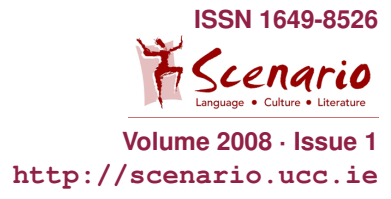

TaT - Texts around Theatre - TaT

\title{
Defeat and After
}

\author{
Peter Jankowsky
}

\begin{abstract}
The German actor and author Peter Jankowsky, living in Ireland, tells (in one of his contributions for Irish radio) of an experience from his schooldays which influenced his whole life. He and another member of their theatre-group were competing for the right to recite a particular poem. He lost - a failure which had surprisingly positive consequences.
\end{abstract}

\section{Defeat and After}

For a couple of years the drama group in our West Berlin school was blessed with two protagonists who, equally talented, complemented each other perfectly. Klaus Hoffmann was blond and freckled; his square face with pale blue eyes often showed a thin, impish grin; his stout body seemed to work like a magnet on his arms - only the most necessary, most incisive gestures would escape. His stage presence was magisterial, thanks mainly to his prime asset, a glorious bass voice, warm, sandy, with an edge, and well-controlled. A voice is one thing, though; you also need the mind to do something with it, and Klaus's mind was bright as well as naturally mature; in fact, you could only imagine him having been born mature and dignified, and crying, if he ever did, in a soothing bass voice.

Having thus presented Klaus in some detail saves me the embarrassment of having to describe the other pillar of our group, namely myself, other than saying that I was, in almost every sense, his opposite - dark-haired, romantic and gesticulating. And naturally immature. No wonder we were regularly cast as opponents on the stage, typically in father-and-son situations, which was not without a touch of irony as Klaus was my junior by at least a year. There would be precious few parts where a director would have to think twice before choosing between the two of us. But on one occasion we were competitors, head to head, mind to mind and voice to voice.

Our group was also involved in regular literary morning services in the school's assembly hall, the texts of the readings usually selected from the works of Hermann Hesse, after whom the school was named. Normally we were assigned certain texts and simply accepted them, but on this occasion Klaus was 
to recite a particular poem which meant a lot to me, and I mentioned that. No problem, I was told, for our next rehearsal Klaus and I should prepare ourselves to audition for the poem, and then a vote would follow. Fine - I felt I had already half-won my case.

The poem, by Hermann Hesse, was titled "Idle Thoughts", but as so often when things are declared 'idle' they are anything but. Written in 1940, the poem shows Hesse's despair and revulsion at yet another European war. Each of the four stanzas is in a starkly contrasting mood. The first predicts a final end to these 'foolishly ingenious' wars, when nothing will be left on earth but the natural world, human history, mankind itself having been extinguished and forgotten. And forgotten as well would be all the beautiful things: children's play, languages, music - 'everything that our loving has inscribed into the willing Earth'. Earth will have no light anymore. The last stanza brings in the Creator who had watched with equanimity the end of 'all the horrible and all the lovely'. He looks at the liberated planet as it hovers darkly amidst the sparkling stars. Pensively he grasps a handful of clay and, once again, begins giving it shape...

I must have been around 18 then, and the poem expressed my own feelings towards the flawed species I found myself belonging to - emotions dithering between hope and despair, pity and contempt. I also harboured my first doubts about the Creator's benevolence towards, or even interest in, His creation. But the real satisfaction lay not in finding my own, vague enough, feelings expressed in the poem, but in finding them expressed so beautifully: the grim firmness of the phrasing, the soulful fall of the lines, the intricate but unlaboured finality of the rhymes. In short: I had been hit by a work of art. Here was a form into which I could pour my shapelessness. And so I prepared myself carefully for our joust, feeling confident.

In the event, there was hardly a contest. I put into my recitation all I had - which was too much. Klaus gave the measured, newsreader delivery I had expected and had wanted to counteract. The vote was clearly in his favour and, to be honest, I couldn't argue with it. His interpretation, if it was one, was objective, and objectivity, in matters of art, is an indisputable quality.

Nevertheless - I had lost when and where it counted, and I felt absolutely vanquished. But, strangely, not weakened, not discouraged. Rather the opposite: a surprisingly nourishing, forward-looking stubbornness arose in me out of my failure, a conviction that I had found what gave me the greatest satisfaction, perhaps even a sense of direction. Or had it found me? Was it even a calling? If so, a very small one, nothing to boast about. But there could be no question of ever letting my discovery slip away again. Instead, I continued doing that which brought with it the joys of self-discovery time and again - serving the word, the poetic word, with the limited means at my command - voice, insight, imagination. Reading and reciting poems or stories became the red thread that has run through my entire life, perhaps even kept it from unravelling. The ball of thread left in my hands is small by now, and if I could wrap it all up again, it would lead me back through the maze of my life, through all the rooms I 
have been in as a word-worker - stages of all sizes, studios of several kinds, classrooms and lecture halls, bar-rooms and bedrooms, the poetry-translator's torture chamber and the quiet room of disquiet which the poet inhabits. The thread even helped me across the gulf between two countries, two cultures. And if I were to follow it all the way back to the beginning, I would finally arrive at the entrance to my private labyrinth and find the thread slung there around a standing stone - the memorial to a most necessary defeat over some anything but idle thoughts.

From:

Peter Jankowsky (2000): Myself Passing By. A Memoir in Moments.

Dublin: New Island, 53-56. 